\title{
Is there a role for segmental adrenal venous sampling and adrenal sparing surgery in patients with primary aldosteronism?
}

\author{
Fumitoshi Satoh ${ }^{1,2, *}$, Ryo Morimoto ${ }^{2, *}$, Kazumasa Seiji ${ }^{3}$, Nozomi Satani ${ }^{3}$, \\ ${\text { Hideki } \text { Ota }^{3} \text {, Yoshitsugu Iwakura }}^{2}$, Yoshikiyo Ono ${ }^{2}$, Masataka Kudo', \\ Masahiro Nezu ${ }^{2}$, Kei Omata ${ }^{1,2}$, Yuta Tezuka ${ }^{1,2}$, Yoshihide Kawasaki ${ }^{4}$, \\ Shigeto Ishidoya ${ }^{4}$, Yoichi Arai ${ }^{4}$, Kei Takase ${ }^{3}$, Yasuhiro Nakamura ${ }^{5}$, \\ Keely McNamara ${ }^{5}$, Hironobu Sasano ${ }^{5}$ and Sadayoshi Ito $^{2}$
}

'Division of Clinical Hypertension, Endocrinology and Metabolism, Tohoku University Graduate School of Medicine, Sendai, Miyagi, Japan, ${ }^{2}$ Division of Nephrology, Endocrinology and Vascular Medicine, Department of Medicine, ${ }^{3}$ Department of Diagnostic Radiology, ${ }^{4}$ Department of Urology and ${ }^{5}$ Department of Pathology, Tohoku University Hospital, Sendai, Miyagi 980-8574, Japan

*(F Satoh and R Morimoto contributed equally to this work)

Correspondence should be addressed to F Satoh Email fsatoh@med.tohoku.ac.jp

\begin{abstract}
Objective and design: Adrenal venous sampling (AVS) is critical to determine the subtype of primary aldosteronism (PA). Central AVS (C-AVS) - that is, the collection of effluents from bilateral adrenal central veins (CV) - sometimes does not allow differentiation between bilateral aldosterone-producing adenomas (APA) and idiopathic hyperaldosteronism. To establish the best treatment course, we have developed segmental AVS (S-AVS); that is, we collect effluents from the tributaries of CV to determine the intra-adrenal sources of aldosterone overproduction. We then evaluated the clinical utility of this novel approach in the diagnosis and treatment of PA.

Methods: We performed C-AVS and/or S-AVS in 297 PA patients and assessed the accuracy of diagnosis based on the results of C-AVS $(n=138,46.5 \%)$ and S-AVS $(n=159,53.5 \%)$ by comparison with those of clinicopathological evaluation of resected specimens.

Results: S-AVS demonstrated both elevated and attenuated secretion of aldosterone from APA and non-tumorous segments, respectively, in patients with bilateral APA and recurrent APA. These findings were completely confirmed by detailed histopathological examination after surgery. S-AVS, but not C-AVS, also served to identify APA located distal from the CV. Conclusions: Compared to C-AVS, S-AVS served to identify APA in some patients, and its use should expand the pool of patients eligible for adrenal sparing surgery through the identification of unaffected segments, despite the fact that S-AVS requires more expertise and time. Especially, this new technique could enormously benefit patients with bilateral or recurrent APA because of the preservation of non-tumorous glandular tissue.
\end{abstract}

\section{Introduction}

Primary aldosteronism (PA) is the most common cause of secondary hypertension worldwide. PA patients have a higher prevalence of cardio-cerebral complications compared to age-matched essential hypertension $(1,2)$.
However, PA can be caused by a number of different underlying medical conditions associated with abnormal secretion of aldosterone from the adrenals, including aldosterone-producing adenomas (APA) and idiopathic
(C) 2015 European Society of Endocrinology Printed in Great Britain
Published by Bioscientifica Ltd. 
hyperaldosteronism (IHA); besides, either disease can be unilateral or bilateral. It is important to determine laterality of the disease, because in general, patients with unilateral disease are subjected to laparoscopic unilateral adrenalectomy while those with bilateral disease are managed pharmacologically. Likewise, the differentiation between IHA and APA is important as APA is considered to be surgically curable.

Adrenal venous sampling (AVS) has been established as the only reliable clinical method to differentiate unilateral from bilateral disease in patients with PA $(3,4,5)$. However, despite those advances, clinical differentiation of bilateral APA from bilateral IHA can be very difficult sometimes, even after successful AVS. In addition, AVS protocols vary among centers in the following aspects: the procedure of sampling (simultaneous or sequential bilateral sampling), the mode of stimulation (unstimulated, continuous or bolus infusion of cosyntropin), and the adoption of selectivity index (SI) and lateralization index (LI) $(5,6,7)$, thus, cross comparison of the results can prove challenging. Some investigators have reported that the 'contralateral suppression index (CSI)' could be another key finding to identify the lesions responsible for excess secretion of aldosterone $(6,8,9,10)$. In APA patients with mild-to-moderate secretion of excess aldosterone, especially in those with computed tomography (CT)-undetectable aldosteroneproducing micro-adenoma (micro-APA), some centers have reported to detect laterality of hyperaldosteronism using their own protocols $(11,12)$. In addition, despite the technological and methodological advances detailed above, it remains nearly impossible to definitively differentiate bilateral APA from IHA based only on the results obtained through central AVS (C-AVS) $(13,14,15)$.

Therefore, segmental AVS (S-AVS) has been proposed to provide more precise information regarding the location of lesions responsible for PA within the gland. $\mathrm{S}$-AVS is a refinement of C-AVS in which samples are taken from the tributaries of the central veins $(\mathrm{CV})$ allowing a finer mapping of the aldosterone production within the gland. According to our own clinical experience described in the current study and prior reports $(16,17)$, we consider S-AVS can be expected to contribute to the identification of the intra-adrenal variation of aldosterone secretion in a far more precise fashion. This approach has a number of advantages, for instance, using S-AVS we should be able to extend the indication for adrenal preservation surgery in PA patients based on a preoperative precise mapping of the segments to be resected or preserved. In addition, S-AVS is also expected to be useful in case of multiple adrenocortical nodules - some producing aldosterone and others producing cortisol. However, we must also refer to the disadvantages of this technique, which are principally related to the time, cost, and skills required to accomplish this meticulous procedure. It is necessary to select the subset of patients who could clinically benefit from S-AVS, rather than C-AVS, and we will briefly refer to this aspect in the final section of this report, including its potential role in the refinement of adrenal sparing surgery.

\section{Patients and methods}

\section{Enrollment of patients}

Patients exhibiting symptoms consistent with a clinical diagnosis of PA were referred to our medical center, which is one of the leading PA units within Japan. The diagnosis of PA was confirmed at our center based on baseline aldosterone and renin activity levels, results of the captopril challenge test, adrenal CT scan findings, and AVS, as reported in our previous study (18). Briefly, those who demonstrated both a baseline aldosterone-over-renin activity ratio (ARR) and $50 \mathrm{mg}$ captopril-challenged ARR $\geq 20 \mathrm{ng} / \mathrm{dl}$ per $\mathrm{ng} / \mathrm{ml}$ per $\mathrm{h}$ were confirmed to have PA and subsequently underwent CT and AVS. Low dose (1 mg) and/or high dose $(8 \mathrm{mg})$ dexamethasone suppression tests (DST) were performed to evaluate concomitant autonomous secretion of cortisol using cut-off cortisol values of 3.0 and $1.0 \mu \mathrm{g} / \mathrm{dl}$ respectively. All the participants were registered in our cohort registry of Primary Aldosteronism Sendai Study (PASS), which is the only cohort registry of PA patients in Japan with written informed consent, and the present study was approved by the ethics committee of Tohoku University School of Medicine (\#2014-1-758).

\section{C-AVS and S-AVS}

C-AVS was performed in all the patients enrolled for the present study. In addition, S-AVS was performed after C-AVS in selected patients in a single session. Both C-AVS and S-AVS were performed by experienced interventional radiologists (K Seiji and $\mathrm{K}$ Takase), as reported previously (19). Briefly, 6.5 French (Fr) catheters were inserted via bilateral common femoral veins up to bilateral adrenal $\mathrm{CV}$. The left catheter tip was positioned distal to the diversion of the left inferior phrenic vein and proximal to the diversion of the lateral tributary of the left adrenal vein. In some cases with a common trunk of the right adrenal vein and an accessory hepatic vein, we confirmed that the catheter tip was actually located in the right adrenal vein 
and not in the hepatic venous tributaries. In C-AVS, venous samples were obtained from bilateral adrenal $\mathrm{CV}$ and the external iliac vein at baseline and 15 min after i.v. bolus injection of $200 \mu \mathrm{g}$ cosyntropin (adrenocorticotropic hormone $\left.\left(\mathrm{ACTH}_{1-24}\right)\right)$. Subsequently, cosyntropin was continuously infused at a rate of $50 \mu \mathrm{g} / \mathrm{h}$ from $30 \mathrm{~min}$ after the bolus injection to the end of AVS. Appropriate catheter tip placement was confirmed just before and after sampling by gently injecting a small amount of contrast medium. S-AVS was subsequently performed via insertion of a micro-catheter up to three intra-adrenal first-degree tributary veins on each side. There are usually three major tributary veins in the right adrenal, corresponding to the superior, lateral, and inferior tributaries, and three major tributary veins in the left adrenal, corresponding to the lateral, superior-lateral, and superior-medial tributaries.

Cannulation of a catheter into the $\mathrm{CV}$ or tributary veins was decided as successful based on the SI, which was defined as the ratio of adrenal cortisol concentration divided by cortisol concentration in the external iliac vein with a cut-off value $\geq 5.0$ after cosyntropin stimulation. The laterality of hyperaldosteronism determined by C-AVS was evaluated using the LI, which was defined as a quotient of the aldosterone/cortisol (A/C) ratio obtained from the $\mathrm{CV}$ of the dominant gland divided by that of the other side (6). Localization of the lesion causing hyperaldosteronism was also analyzed based on the LI obtained by S-AVS, which was defined as the $\mathrm{A} / \mathrm{C}$ ratio of the dominant segment divided by the averaged $A / C$ ratio of non-dominant segments.

As S-AVS is a relatively new technique, there are no current studies examining optimal indexes for deciding subsequent patient management. The current suggestion for cosyntropin-stimulated C-AVS is that a cut-off LI of 2.6 is indicative of unilateral adrenalectomy, as previously reported (4). Owing to this we adopted a similar cut-off LI for S-AVS at the beginning of this study; with an LI $<2.6$ defined as the threshold for pharmacological therapy during this study. Therefore, we attempted to determine the actual cut-off LI for S-AVS in this study. The CSI (cutoff value of 1.0), which was defined as a quotient of the adrenal $\mathrm{A} / \mathrm{C}$ ratio divided by that of the external iliac vein (6), was employed to evaluate suppression of aldosterone secretion.

\section{Statistical analysis}

The normality of collected data was analyzed by Kolmogorov-Smirnov test. When continuous variables showed a Gaussian distribution, one-way ANOVA was employed for comparison. When continuous variables showed no normality of distribution, the Kruskal-Wallis test with the Dunn's multiple comparison test as a post-hoc test was used. Statistical significance was set at $P \leq 0.05$.

\section{Results}

\section{Subtype analysis based on C-AVS and S-AVS}

A total of 322 consecutive patients from the PASS registry were enrolled in the present study. In a previous report on the radiological aspects of S-AVS (19), 64 patients were enrolled and these patients were all included in the present study. One patient, excluded from that previous report (19) due to a history of unilateral adrenalectomy for unilateral APA, was also included in this study to evaluate the clinical significance of S-AVS in recurrent unilateral APA. Of the 322 patients originally selected, 297 participants were included. The other 25 participants were excluded because of ineligibility for various reasons: unsuccessful sampling with SI $<5.0(n=1)$, concomitant autonomous secretion of cortisol $(n=17)$, no information as to histopathological findings in the resected adrenal $(n=7)$. Yet, three patients who were suspected of having recurrent PA after adrenalectomy for unilateral APA were also enrolled.

The eligible 297 patients were tentatively classified into the following two groups depending on the type of sampling: C-AVS ( $n=138,46.5 \%)$ and C-AVS followed by S-AVS ( $n=159,53.5 \%$ ) (Table 1$)$. Within the C-AVS group, patients were further sub-classified based on LI and subsequent medical management. Patients with a LI $\geq 2.6(n=44,31.9 \%$, LI mean \pm s.e.M. $=10.4 \pm 1.69$, range 2.68-55.6) and unilateral disease underwent adrenalectomy, while the others with a LI $<2.6(n=94,68.1 \%$, LI $1.34 \pm 0.032$, range $1.01-2.24$ ) were diagnosed with bilateral PA and underwent specific pharmacological treatment including mineralocorticoid receptor antagonists (MRA) $(n=94,68.1 \%)$.

The patients who underwent S-AVS were similarly divided into the adrenalectomy ( $n=100,62.9 \%$, LI $17.0 \pm$ 1.49 , range 3.07-81.9) and medical management $(n=59$, $37.2 \%$, LI $1.53 \pm 0.054$, range $1.03-2.56)$ groups on the basis of their LI. Patient grouping by this detailed mapping technique is exemplified by the five cases described in the following section, but the overall details of the cohort will be given here. Of the 59 patients assigned to a specific pharmacological regimen, 58 had bilateral PA with a LI $<2.6$, and the remaining patient, who had undergone left adrenalectomy for ipsilateral APA, had elevated 
Table 1 Demographic and baseline data. Data were shown as mean \pm s.E.M., unless otherwise stated.

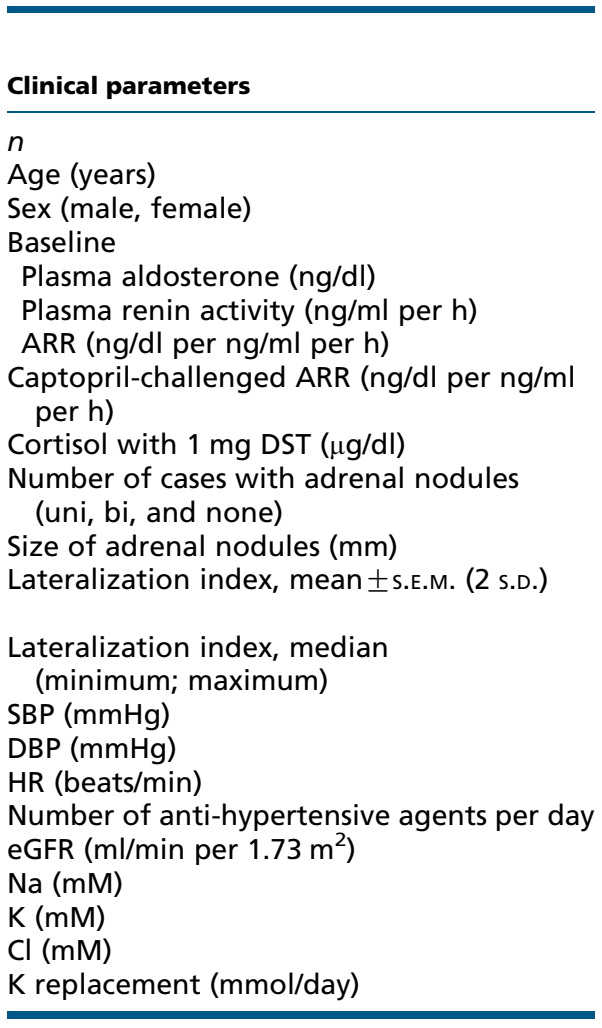

\begin{tabular}{|c|c|}
\hline \multicolumn{2}{|c|}{ C-AVS } \\
\hline Pharmacological & Adrenalectomy \\
\hline 94 & 44 \\
\hline $55.8 \pm 1.02$ & $54.5 \pm 2.02$ \\
\hline 27,67 & 23,21 \\
\hline $13.6 \pm 0.764$ & $32.6 \pm 3.93$ \\
\hline $0.190 \pm 0.0187$ & $0.166 \pm 0.0181$ \\
\hline $94.1 \pm 5.05$ & $280.3 \pm 42.1$ \\
\hline $63.5 \pm 4.11$ & $193.2 \pm 32.7$ \\
\hline $0.917 \pm 0.0362$ & $1.13 \pm 0.0789$ \\
\hline $19,5,70$ & $27,2,15$ \\
\hline $12.3 \pm 0.781$ & $16.1 \pm 1.24$ \\
\hline$\frac{1.34 \pm 0.032}{(0.61)}$ & $10.4 \pm 1.69(20.8)$ \\
\hline $1.25(1.01 ; 2.24)$ & $7.23(2.68 ; 55.6)$ \\
\hline $148.8 \pm 2.12$ & $153.3 \pm 3.18$ \\
\hline $90.1 \pm 1.34$ & $91.9 \pm 2.30$ \\
\hline $80.5 \pm 1.48$ & $74.6 \pm 2.20$ \\
\hline $1.50 \pm 0.122$ & $2.47 \pm 0.271$ \\
\hline $75.8 \pm 1.53$ & $77.9 \pm 3.19$ \\
\hline $141.5 \pm 0.178$ & $143.2 \pm 0.335$ \\
\hline $4.34 \pm 0.0451$ & $3.77 \pm 0.0985$ \\
\hline $106.3 \pm 0.192$ & $105.1 \pm 0.373$ \\
\hline $3.62 \pm 1.15$ & $12.8 \pm 2.41$ \\
\hline
\end{tabular}

\begin{tabular}{|c|c|c|}
\hline \multicolumn{2}{|c|}{ S-AVS } & \multirow[b]{2}{*}{$P$ values } \\
\hline Pharmacological & Adrenalectomy & \\
\hline $\begin{array}{c}59 \\
52.8 \pm 1.45 \\
26,34\end{array}$ & $\begin{array}{c}100 \\
53.3 \pm 1.06 \\
65,34\end{array}$ & \\
\hline $\begin{array}{c}15.7 \pm 0.928 \\
0.218 \pm 0.0222 \\
101.1 \pm 8.38 \\
65.7 \pm 5.53\end{array}$ & $\begin{array}{c}41.0 \pm 3.46 \\
0.208 \pm 0.0173 \\
313.5 \pm 36.8 \\
199.9 \pm 27.7\end{array}$ & $\begin{array}{l}<0.05^{\mathrm{a}, \mathrm{b}} \\
<0.05^{\mathrm{a}, \mathrm{b}} \\
<0.05^{\mathrm{a}, \mathrm{b}}\end{array}$ \\
\hline $\begin{array}{c}0.874 \pm 0.0314 \\
22,3,34\end{array}$ & $\begin{array}{c}1.10 \pm 0.0491 \\
75,14,11\end{array}$ & \\
\hline $\begin{array}{c}13.7 \pm 0.848 \\
1.53 \pm 0.054 \\
(0.82) \\
1.47(1.03 ; 2.56)\end{array}$ & $\begin{array}{c}14.7 \pm 0.645 \\
17.0 \pm 1.49(28.1) \\
12.0(3.07 ; 81.9)\end{array}$ & \\
\hline $\begin{array}{c}148.9 \pm 2.67 \\
92.1 \pm 2.09\end{array}$ & $\begin{array}{l}151.2 \pm 2.07 \\
94.8 \pm 1.42\end{array}$ & \\
\hline $\begin{array}{c}78.2 \pm 1.81 \\
1.57 \pm 0.167\end{array}$ & $\begin{array}{c}77.1 \pm 1.55 \\
2.67 \pm 0.163\end{array}$ & $<0.05^{a, b}$ \\
\hline $\begin{array}{c}75.2 \pm 1.62 \\
141.1+0.262\end{array}$ & $\begin{array}{c}77.9 \pm 1.81 \\
142.1+0.178\end{array}$ & \\
\hline $4.31 \pm 0.0631$ & $3.98 \pm 0.0492$ & $<0.05^{\mathrm{a}, \mathrm{b}}$ \\
\hline $106.1 \pm 0.295$ & $105.7 \pm 0.238$ & $<0.05^{a, b}$ \\
\hline $11.5 \pm 2.76$ & $44.5 \pm 3.75$ & $<0.05^{a, b}$ \\
\hline
\end{tabular}

C-AVS, central adrenal venous sampling; S-AVS, segmental adrenal venous sampling; ARR, aldosterone-over-renin activity ratio; DST, dexamethasone suppression test; uni, unilateral; bi, bilateral; SBP, systolic blood pressure; DBP, diastolic blood pressure; HR, heart rate; eGFR, estimated glomerular filtration rate.

${ }^{a}$ Denotes statistical significance in comparison between pharmacological and adrenalectomy subgroups in C-AVS group.

${ }^{\mathrm{b}}$ Denotes statistical significance in comparison between pharmacological and adrenalectomy subgroups in S-AVS group.

aldosterone levels at every sampling point within the remaining right adrenal gland without suppressed aldosterone secretion, indicating no room for partial resection of the gland. Within the medical management subgroup, $23(14.5 \%)$ out of the 58 patients with bilateral diseases corresponded to IHA with non-functioning tumors (as shown in case 3 in the following section), and the other 35 patients $(22.0 \%)$ had IHA without adrenal nodules. Within the patients allocated to the adrenalectomy group (LI $\geq 2.6$ ), the following clinical subgroups were found; 91 patients (57.2\%) had unilateral APA (case 1 in the following case series section is a typical case), three patients (1.9\%) showed an elevated value of $\mathrm{A} / \mathrm{C}$ ratio only at the tumor segment of the gland in contrast to suppressed secretion at the other sampling points by S-AVS (exemplified by case 2 ), four patients $(2.5 \%)$ were diagnosed bilateral CT-detectable APA (corresponding to representative case 4$)$, and two patients (1.3\%) were diagnosed recurrent APA in the remaining gland after the first adrenalectomy for the contralateral APA (corresponding to representative case 5). This demonstrates that there were two subgroups of patients in whom better outcomes could be achieved on the basis of results from S-AVS: those represented by case $2(n=3,1.9 \%)$, who turned out to be potential candidates for unilateral adrenalectomy based on the findings of S-AVS but not C-AVS, and those represented by cases 4 and 5 ( $n=4$ plus 2, 3.8\%), who underwent adrenal sparing surgery because of S-AVS findings. Therefore, $5.7 \%(n=9)$ of the patients who underwent S-AVS benefitted from this sampling technique.

In evaluating the differences between LI of S-AVS and that of C-AVS, we found no significant differences in values in the pharmacological or adrenalectomy groups. When examining the LI values obtained through S-AVS, the minimum value of $\mathrm{LI}$ in the adrenalectomy group and the maximum value of LI in the pharmacological group were 3.07 and 2.56 respectively. Furthermore, the mean + 2 s.D. in the pharmacological group was $1.53+0.82=2.35$ as shown in Table 1 . Therefore, these findings can suggest that the cut-off of LI in S-AVS should be 2.6-3.0. 


\section{Clinical and endocrinological evaluation}

When the C-AVS and S-AVS subgroups within the adrenalectomy and pharmacologically treated patients were examined, there were no significant differences in multiple clinical factors (baseline aldosterone, renin activity, ARR, and captopril-challenged ARR levels, number of anti-hypertensive agents, serum levels of potassium and chloride). In contrast, comparison between pharmacological and adrenalectomy group as a whole showed significant differences in multiple clinical parameters including elevated levels of baseline aldosterone, ARR, captopril-challenged ARR, number of anti-hypertensive agents, and amount of potassium replacement, regardless of the type of sampling. Also, there were significantly lower levels of serum potassium and chloride in the adrenalectomy group. The exception to this was that baseline renin activity levels did not differ significantly between the adrenalectomy and pharmacological management groups. Finally, there were no significant differences among the subgroups regarding diameter of adrenal nodules, systolic and diastolic blood pressures, and heart rate.

Seven days after the surgery, significantly lower levels of aldosterone were detected in the adrenalectomy subgroups (C-AVS: $7.67 \pm 0.506 \mathrm{ng} / \mathrm{dl}$ and S-AVS: $7.30 \pm$ $0.319 \mathrm{ng} / \mathrm{dl}$ ) compared to values before the surgery, as well as significantly lower levels of blood pressures (systolic and diastolic), heart rate, number of pharmacological agents, and dosage of potassium replacement (Table 2). Comparison between the adrenalectomy C-AVS and S-AVS subgroups showed no significant differences in the following parameters: postoperative levels of aldosterone, renin activity, blood pressure, number of anti-hypertensive agents, estimated glomerular filtration rate, serum electrolytes, and requirement of potassium replacement. Similarly, in those with specific pharmacological treatment including MRA, significant differences were detected at the latest follow-up evaluations when compared to baseline: blood pressure (both systolic and diastolic), heart rate, number of medications, serum potassium level, and amount of potassium replacement (Table 2).

\section{Comparison of complications and costs}

In terms of complications and costs, we found minor extravasation in $20(12.6 \%)$ out of 159 patients during S-AVS, in contrast to only 5 (3.6\%) out of 138 in the C-AVS group. During S-AVS, extravasation was detected when a very small amount of contrast medium was injected into a tributary vein via a micro-catheter to confirm the sampling point. All of these adverse events, which happened during both S-AVS and C-AVS, resolved spontaneously without requirement for additional management such as embolization.

In terms of costs, S-AVS is significantly more expensive than C-AVS. In our center, two catheters for bilateral sampling and a ready-made angiography kit including sheath introducers and a guidewire with $60 \mathrm{ml}$ of iodine contrast medium were employed for C-AVS, at a cost of $\sim \$ 160$ US (19000 yen). In addition to these,

Table 2 Outcome data after specific treatment. Data were shown as mean \pm s.E.M., unless otherwise stated.

\begin{tabular}{|c|c|c|c|c|c|}
\hline \multirow[b]{2}{*}{ Clinical parameters } & \multicolumn{2}{|c|}{ C-AVS } & \multicolumn{2}{|c|}{ S-AVS } & \multirow[b]{2}{*}{$P$ values } \\
\hline & Pharmacological & Adrenalectomy & Pharmacological & Adrenalectomy & \\
\hline$n$ & 94 & 44 & 59 & 100 & \\
\hline \multicolumn{6}{|l|}{ Baseline on postoperative day 7} \\
\hline Plasma aldosterone (ng/dl) & NA & $7.67 \pm 0.506$ & NA & $7.30 \pm 0.319$ & $<0.05^{\mathrm{a}}$ \\
\hline Plasma renin activity ( $\mathrm{ng} / \mathrm{ml}$ per $\mathrm{h}$ ) & NA & $0.557 \pm 0.112$ & NA & $0.682 \pm 0.0986$ & \\
\hline $\mathrm{SBP}(\mathrm{mmHg})$ & $122.9 \pm 1.60$ & $123.8 \pm 1.66$ & $123.4 \pm 1.57$ & $125.1 \pm 1.42$ & $<0.05^{a, b}$ \\
\hline $\mathrm{DBP}(\mathrm{mmHg})$ & $76.9 \pm 1.26$ & $76.9 \pm 1.29$ & $78.7 \pm 1.37$ & $79.5 \pm 1.06$ & $<0.05^{\mathrm{a}, \mathrm{b}}$ \\
\hline HR (beats/min) & $73.5 \pm 1.24$ & $63.9 \pm 1.51$ & $72.4 \pm 1.50$ & $67.2 \pm 1.30$ & $<0.05^{a, b}$ \\
\hline $\begin{array}{l}\text { Number of anti-hypertensive } \\
\text { agents per day }\end{array}$ & $2.64 \pm 0.160$ & $0.954 \pm 0.160$ & $2.68 \pm 0.146$ & $0.783 \pm 0.0886$ & $<0.05^{\mathrm{a}, \mathrm{b}}$ \\
\hline eGFR $\left(\mathrm{ml} / \mathrm{min}\right.$ per $\left.1.73 \mathrm{~m}^{2}\right)$ & $78.6 \pm 3.18$ & $66.5 \pm 2.70$ & $70.1 \pm 2.60$ & $66.6 \pm 1.85$ & \\
\hline $\mathrm{Na}(\mathrm{mM})$ & $139.7 \pm 0.470$ & $140.7 \pm 0.269$ & $140.1 \pm 0.300$ & $139.4 \pm 0.201$ & \\
\hline $\mathrm{K}(\mathrm{mM})$ & $4.30 \pm 0.0562$ & $4.58 \pm 0.0567$ & $4.31 \pm 0.0470$ & $4.59 \pm 0.0404$ & $<0.05^{a, b}$ \\
\hline $\mathrm{Cl}(\mathrm{mM})$ & $103.0 \pm 0.479$ & $105.4 \pm 0.317$ & $104.1 \pm 0.409$ & $105.1 \pm 0.215$ & \\
\hline $\mathrm{K}$ replacement (mmol/day) & 0 & 0 & 0 & 0 & $<0.05^{a, b}$ \\
\hline
\end{tabular}

C-AVS, central adrenal venous sampling; S-AVS, segmental adrenal venous sampling; SBP, systolic blood pressure; DBP, diastolic blood pressure; HR, heart rate; eGFR, estimated glomerular filtration rate; NA, not applicable.

aDenotes statistical significance in comparison between before and after adrenalectomy in adrenalectomy subgroup of C-AVS or S-AVS group.

${ }^{b}$ Denotes statistical significance in comparison between before and after specific medication in pharmacological subgroup of C-AVS or S-AVS group. 


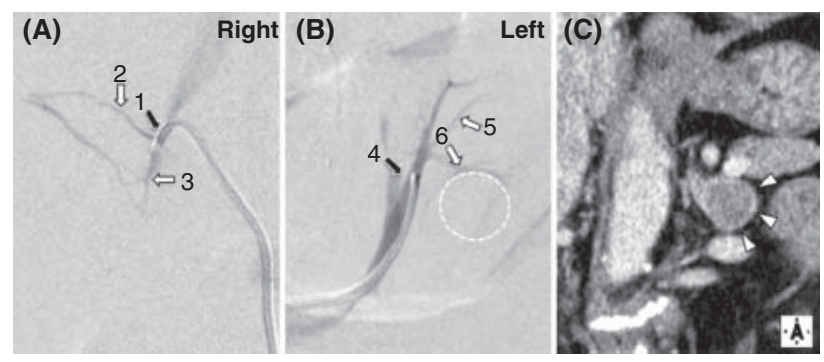

\section{Figure 1}

Adrenal venography performed to carry out S-AVS ( $A$, right side; $B$, left side) and coronal CT image of the left adrenal gland (C) in a 63-year-old man who was finally diagnosed unilateral APA. The adrenal tumor was detected by $C T$ ( $C$, arrowheads) and projected into the venography ( $B$, dotted circle). Sampling points from central veins are indicated by black arrows 1 and 4 in $(A)$ and $(B)$ respectively. Sampling points from tributary veins are indicated by white arrows 2 and 3 in (A) and 5 and 6 in (B). Each number (1-6) in the venography corresponds to that of the sampling point in Table 3.

a micro-catheter, a micro-guidewire and $40 \mathrm{ml}$ of iodine contrast medium were required for S-AVS resulting in an approximate cost of $\$ 690$ US (82 000 yen). These figures only take into account the equipment needed for the procedure and do not include additional costs associated with prolonged labor time of highly skilled professional angiographers and the costs of the additional number of hormone assays to measure the concentration of aldosterone in samples obtained from each tributary vein.

\section{Case series}

As mentioned above we have chosen five representative cases that exemplify the potential clinical implications and benefits of the use of S-AVS to determine the cause of PA.
Case 1: unilateral APA eligible for partial adrenal resection - This was the case of a 63-year-old man whose final diagnosis was unilateral APA. Figure 1 shows adrenal venography performed to carry out S-AVS (A, right; B, left) and coronal CT image of the left adrenal gland (C). A nodule detected by CT (C, arrowheads) was localized in the lateral segment of the left adrenal gland (B, dotted circle). The C-AVS and S-AVS findings are summarized in Table 3. The SI was more than 5.0 at every sampling point of $\mathrm{CV}$ and tributary veins. Based on these C-AVS findings, LI was calculated as high as 57.5 (47.17/0.82; > 2.6) and CSI was 0.098 (0.82/8.4; <1.0), suggesting unilateral disease with a clinical indication of unilateral (left) adrenalectomy. The highest A/C ratio (67.18) and aldosterone level (60 $328 \mathrm{ng} / \mathrm{dl}$ ) were obtained by S-AVS of a tributary drainage vein of an APA segment (sampling point 6). In contrast, S-AVS revealed suppressed secretion of aldosterone from bilateral non-tumor segments with $\mathrm{A} / \mathrm{C}$ ratios ranging from 0.89 to 1.25 (mean 1.02), all of which were less than that in the external iliac vein (8.4) resulting in the corresponding CSI values of $0.10-0.15(<1.0)$. Therefore, S-AVS should make it possible to consider a partial resection of the left adrenal gland, instead of total adrenalectomy, for the management of PA in this case.

Case 2: APA localized distal from the CV $\bullet$ This was the case of a 55-year-old woman whose final diagnosis was unilateral APA. Figure 2 shows adrenal venography during S-AVS (A, right; B, left) and coronal CT image of the left adrenal gland $(\mathrm{C})$. A cortical nodule was identified in the periphery of the left adrenal gland (B, dotted circle; $\mathrm{C}$, arrowheads). The C-AVS and S-AVS findings are summarized in Table 4. The SI was more than 5.0 at every sampling point in the CV and tributary veins. Based on C-AVS findings, LI was calculated to be $1.4(2.13 / 1.47$; $<2.6)$, which was suggestive of bilateral disease.

Table 3 AVS findings of case 1; unilateral APA eligible for partial adrenal resection.

\begin{tabular}{|c|c|c|c|c|c|c|c|}
\hline \multirow[b]{2}{*}{ Measurements } & \multirow[b]{2}{*}{ EIV } & \multicolumn{3}{|c|}{ Right adrenal } & \multicolumn{3}{|c|}{ Left adrenal } \\
\hline & & $\mathrm{CV}$ & $\begin{array}{c}\text { Non-tumor } \\
\text { segment }\end{array}$ & $\begin{array}{c}\text { Non-tumor } \\
\text { segment }\end{array}$ & CV & $\begin{array}{c}\text { Non-tumor } \\
\text { segment }\end{array}$ & APA segment \\
\hline Sampling point & & 1 & 2 & 3 & 4 & 5 & 6 \\
\hline Aldosterone (ng/dl) & 112.5 & 477 & 448 & 614 & 28974 & 521 & 60328 \\
\hline Cortisol ( $\mu \mathrm{g} / \mathrm{dl})$ & 13.4 & 585 & 358 & 689 & 614 & 570 & 898 \\
\hline $\mathrm{A} / \mathrm{C}$ ratio & 8.4 & 0.82 & 1.25 & 0.89 & 47.17 & 0.91 & 67.18 \\
\hline SI & NA & 43.7 & 26.7 & 51.4 & 45.8 & 42.5 & 67.0 \\
\hline CSI & NA & 0.098 & 0.15 & 0.10 & 5.62 & 0.11 & 8.00 \\
\hline
\end{tabular}

SI, selectivity index; CSI, contralateral suppression index; APA, aldosterone-producing adenoma; A/C ratio, ratio of aldosterone over cortisol; EIV, external iliac vein; CV, central vein; NA, not applicable. 


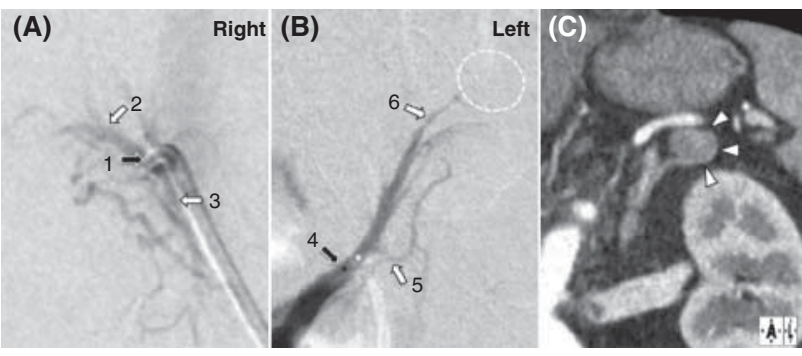

\section{Figure 2}

Adrenal venography performed to carry out S-AVS (A, right side; $B$, left side) and coronal CT image of the left adrenal gland (C) in a 55-year-old woman who was finally diagnosed unilateral APA. The adrenal tumor was detected by CT ( $C$, arrowheads) and projected into the venography ( $B$, dotted circle). Sampling points from central veins are indicated by black arrows 1 and 4 in (A) and (B) respectively. Sampling points from tributary veins are indicated by white arrows 2 and 3 in $(A)$ and 5 and 6 in (B). Each number (1-6) in the venography corresponds to that of the sampling point in Table 4.

Of particular interest, the values of CSI were $<1.0$ bilaterally; right-over-peripheral CSI was $0.46(1.47 / 3.18)$ and left-over-peripheral CSI was 0.67 (2.13/3.18). These findings showed that C-AVS findings were not sufficient to identify possible lesions within each adrenal gland and the lack of clarity in C-AVS was one of the prime reasons to perform S-AVS in this patient. Sampling from a tributary proximal to the tumor (sampling point 6) was the only point that showed a higher A/C ratio (33.49) compared to the external iliac vein (3.18). A/C ratios obtained by sampling from bilateral non-tumor segments (sampling points 2, 3, and 5) were found to be less than the A/C ratio in the external iliac vein, indicating suppressed secretion of aldosterone from these non-tumor segments. All the CSI values obtained from bilateral CV and tributary veins were $<1.0(0.24-0.67)$, with the possible exception of that from the tumor segment. On the basis of the fine lesions mapped by S-AVS, we hypothesized that the blood flow from non-tumor segments, especially those in a distal location, may dilute the overall aldosterone concentrations measured by C-AVS, thus minimizing its diagnostic ability in this case.

Based on the above S-AVS findings, the present patient underwent total left adrenalectomy and was finally diagnosed APA distal to the central venous network of the adrenal. This case exemplifies that in cases in which C-AVS fails to provide sufficient evidence of APA to determine the diagnosis of unilateral disease and subsequent surgical management, S-AVS can provide the required additional diagnostic information. This may be especially relevant in cases in which other diagnostic information, such as elevated peripheral concentrations of aldosterone and presence of adrenal tumors on CT images, is strongly suggestive of APA.

Case 3: IHA in a patient harboring a clinically nonfunctioning tumor $>$ This patient was a 63-year-old man bearing a non-functioning adenoma (NFA) and who was finally diagnosed IHA. Figure 3 illustrates adrenal venography during S-AVS (A, right; B, left) and coronal CT image of the right adrenal gland (C). A right adrenal tumor was depicted by CT (C, arrowheads) and venography (A, dotted circle). Both C-AVS and S-AVS findings are summarized in Table 5. All the SI values were more than 5.0 at every sampling point in $\mathrm{CV}$ and tributary veins. Based on those C-AVS findings, LI was calculated to be $1.34(3.21 / 2.39 ;<2.6)$ and CSI was also more than 1.0 (right, 2.77; left, 2.06), indicating bilateral disease requiring pharmacological treatment. To investigate whether the right adrenal tumor represented APA or not, S-AVS was performed. Within the right adrenal, the A/C ratios obtained from both tumor and non-tumor segments

Table 4 AVS findings of case 2; APA localized distal from the CV.

\begin{tabular}{|c|c|c|c|c|c|c|c|}
\hline \multirow[b]{2}{*}{ Measurements } & \multirow[b]{2}{*}{ EIV } & \multicolumn{3}{|c|}{ Right adrenal } & \multicolumn{3}{|c|}{ Left adrenal } \\
\hline & & CV & $\begin{array}{l}\text { Non-tumor } \\
\text { segment }\end{array}$ & $\begin{array}{c}\text { Non-tumor } \\
\text { segment }\end{array}$ & CV & $\begin{array}{c}\text { Non-tumor } \\
\text { segment }\end{array}$ & APA segment \\
\hline Sampling point & & 1 & 2 & 3 & 4 & 5 & 6 \\
\hline Aldosterone (ng/dl) & 42.9 & 749.1 & 564.0 & 354.0 & 1159.3 & 383.0 & 13582.7 \\
\hline Cortisol ( $\mu \mathrm{g} / \mathrm{dl})$ & 13.5 & 509.9 & 376.2 & 471.9 & 544.5 & 445.8 & 405.6 \\
\hline A/C ratio & 3.18 & 1.47 & 1.50 & 0.75 & 2.13 & 0.86 & 33.49 \\
\hline SI & NA & 37.8 & 27.9 & 35.0 & 40.3 & 33.0 & 30.0 \\
\hline CSI & NA & 0.46 & 0.47 & 0.24 & 0.67 & 0.27 & 10.50 \\
\hline
\end{tabular}

SI, selectivity index; CSI, contralateral suppression index; APA, aldosterone-producing adenoma; A/C ratio, ratio of aldosterone over cortisol; EIV, external iliac vein; CV, central vein; NA, not applicable. 


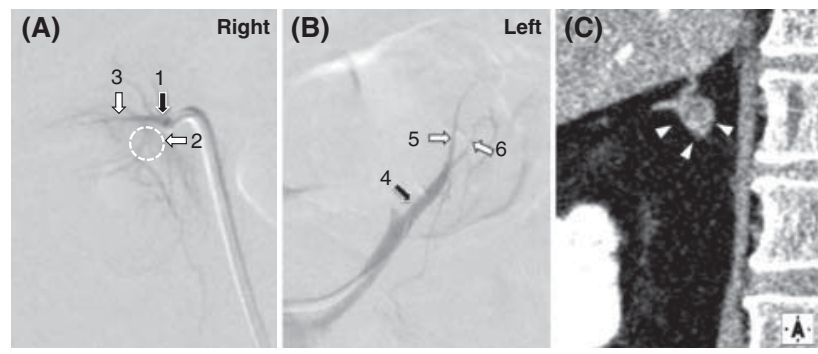

\section{Figure 3}

Adrenal venography performed to carry out S-AVS (A, right side; $B$, left side) and coronal CT image of the right adrenal gland $(C)$ in a 63-year-old man who was finally diagnosed IHA with a concomitant non-functioning adenoma. The adrenal tumor was detected by $\mathrm{CT}$ (C, arrowheads) and projected into the venography ( $A$, dotted circle). Sampling points from central veins are indicated by black arrows 1 and 4 in (A) and (B) respectively. Sampling points from tributary veins are indicated by white arrows 2 and 3 in (A) and 5 and 6 in (B). Each number (1-6) in the venography corresponds to that of the sampling point in Table 5.

(corresponding to sampling points 2 and 3 ) were 2.20 and 2.27 respectively. The CSI calculated in the non-tumor segment of the right adrenal was $1.96(2.27 / 1.16 ;>1.0)$, suggesting excessive secretion of aldosterone in the nontumor segment. In addition, in the left adrenal, A/C ratios obtained from non-tumor segments and the CV were 2.73, 3.24 , and 2.39, respectively, suggesting no suppressed secretion of aldosterone from the left adrenal gland. Autonomous secretion of cortisol was also clinically ruled out by the DST. Based on the above C-AVS and S-AVS findings, the present case was clinically diagnosed to harbor IHA with NFA. In a typical case of IHA such as this case, A/C ratios of bilateral CV (right, 3.21; left, 2.39) and all tributary veins (2.20-3.24) were usually higher than the $\mathrm{A} / \mathrm{C}$ ratio of the external iliac vein (1.16), and we considered that such patients were by no means candidates for S-AVS.

Case 4: bilateral APA $~$ This was a 66-year-old man who was finally diagnosed bilateral APA. Figure 4 shows the adrenal venography during S-AVS (A, right; $B$, left) and the coronal CT image of bilateral adrenal glands $(\mathrm{C})$. The right adrenocortical nodule detected by CT (C, arrowheads) was localized in the caudal segment of the right adrenal (A, dotted circle). The left adrenal nodule detected by CT (C, arrowheads) was identified in the lateral segment of the left adrenal (B, dotted circle). Both C-AVS and S-AVS findings are summarized in Table 6 . All the SI values were more than 5.0 at every sampling point in CV and tributary veins, and autonomous secretion of cortisol was ruled out by the $1 \mathrm{mg}$ DST showing $1.2 \mu \mathrm{g} / \mathrm{dl}$ cortisol (Table 7; case 4-1). The results of C-AVS indicated bilateral disease with a LI of $2.02(20.2 / 9.99)$. S-AVS was performed to differentiate bilateral APA from IHA with bilateral NFA in the present case. The $\mathrm{A} / \mathrm{C}$ ratios obtained from bilateral tumorsegments were higher than the $\mathrm{A} / \mathrm{C}$ ratio in the external iliac vein (3.80); 40.79 at the right tumor and 31.08 at the left tumor. In contrast, the $\mathrm{A} / \mathrm{C}$ ratios from non-tumor segments were 0.89 and 2.80 , in the right and left adrenal glands, respectively, and were less than that in the external iliac vein (3.80). Consequently, CSI values of bilateral non-tumor segments were $<1.0$ (right, 0.23 ; left, 0.74 ), suggesting suppressed secretion of aldosterone. Taking together CT findings consistent with bilateral adrenocortical tumors and S-AVS findings of excessive secretion of aldosterone from the tumor segments and suppressed secretion from the non-tumor segments, we established the diagnosis of bilateral APA and subsequently decided the patient should undergo adrenal sparing surgery.

Table 5 AVS findings of case 3; IHA in a patient harboring a clinically non-functioning tumor.

\begin{tabular}{l}
\hline Measurements \\
\hline Sampling point \\
Aldosterone $(\mathrm{ng} / \mathrm{dl})$ \\
Cortisol $(\mu \mathrm{g} / \mathrm{dl})$ \\
A/C ratio \\
SI \\
$\mathrm{CSI}$
\end{tabular}

\begin{tabular}{c}
\hline \\
EIV \\
\hline \\
11.7 \\
10.1 \\
1.16 \\
NA \\
NA \\
\hline
\end{tabular}

\begin{tabular}{c}
\hline \\
\hline $\mathrm{CV}$ \\
\hline 1 \\
2494 \\
776 \\
3.21 \\
76.8 \\
2.77 \\
\hline
\end{tabular}

\begin{tabular}{ccc} 
Right adrenal & \\
Tumor segment & & $\begin{array}{c}\text { Non-tumor } \\
\text { segment }\end{array}$ \\
\cline { 1 - 1 } 2 & & 3 \\
2705 & & 3156 \\
1227 & & 1392 \\
2.20 & & 2.27 \\
121.5 & & 137.8 \\
1.90 & & 1.96 \\
\end{tabular}

\begin{tabular}{|c|c|c|}
\hline \multicolumn{3}{|c|}{ Left adrenal } \\
\hline $\mathrm{CV}$ & $\begin{array}{l}\text { Non-tumor } \\
\text { segment }\end{array}$ & $\begin{array}{c}\text { Non-tumor } \\
\text { segment }\end{array}$ \\
\hline 4 & 5 & 6 \\
\hline 2331 & 3626 & 4342 \\
\hline 974 & 1331 & 1340 \\
\hline 2.39 & 2.73 & 3.24 \\
\hline 96.4 & 131.8 & 132.7 \\
\hline 2.06 & 2.35 & 2.79 \\
\hline
\end{tabular}

$\mathrm{SI}$, selectivity index; CSI, contralateral suppression index; IHA, idiopathic hyperaldosteronism; A/C ratio, ratio of aldosterone over cortisol; EIV, external iliac vein; CV, central vein; NA, not applicable. 


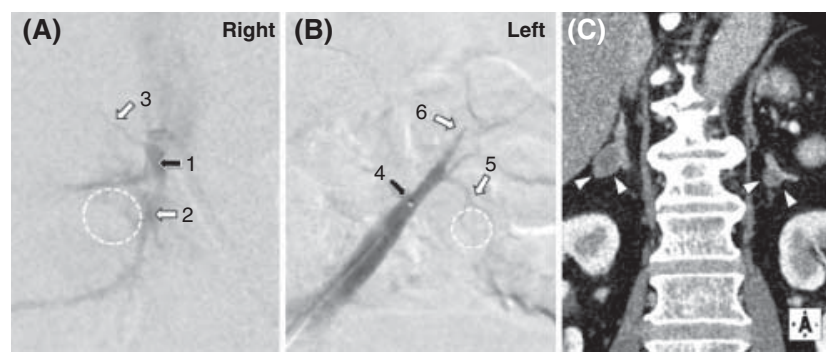

\section{Figure 4}

Adrenal venography performed to carry out S-AVS ( $A$, right; $B$, left) and coronal CT image of the bilateral adrenal gland (C) in a 66-year-old man who was finally diagnosed bilateral APA. The bilateral adrenal tumors were detected by CT ( $C$, arrowheads) and projected into the venography ( $A$ and $B$, dotted circles). Sampling points from central veins are indicated by black arrows 1 and 4 in (A) and (B) respectively. Sampling points from tributary veins are indicated by white arrows 2 and 3 in (A) and 5 and 6 in (B). Each number (1-6) inthe venography corresponds to that of the sampling point in Table 6 .

We then partially resected the right adrenal to spare non-tumor segments and performed total left adrenalectomy in a single session. After the sparing surgery, baseline plasma and urinary aldosterone levels decreased to $5.9 \mathrm{ng} / \mathrm{dl}$ and $0.8 \mu \mathrm{g} /$ day respectively (Table 7 ; case $4-1$ ). His blood pressure also decreased below $140 / 90 \mathrm{mmHg}$ with a smaller number of anti-hypertensive agents than before the surgery. Glucocorticoid replacement was provided immediately after the surgery and tapered gradually until postoperative day 30 without episodes of adrenal insufficiency during the replacement period. At the last follow-up examination, 403 days after the surgery, the baseline aldosterone and renin activity levels were $2.5 \mathrm{ng} / \mathrm{dl}$ and $0.5 \mathrm{ng} / \mathrm{ml}$ per $\mathrm{h}$, respectively, and baseline
ACTH and cortisol levels were $93.6 \mathrm{pg} / \mathrm{ml}$ and $14.4 \mu \mathrm{g} / \mathrm{dl}$ respectively (Table 7; case $4-1$ ).

This case shows clearly the utility of S-AVS in the diagnosis of bilateral APA. A further benefit of this approach in these patients is that, combined with accurate localization of bilateral adrenal tumors by CT, S-AVS can be utilized in the design of adrenal sparing surgery by indicating segments to be resected or spared; thus, by sparing some adrenal tissue, a better postoperative outcome can be achieved in terms of subsequent medical management.

This subcategory deserves further mention as there were three more patients in whom S-AVS facilitated the diagnosis of bilateral APA and the decision of adrenal sparing surgery. Among these three patients, one successfully underwent surgery without any need for subsequent glucocorticoid replacement due to careful planning prior to surgery allowing for preservation of non-tumor segments. Such clinical success was achieved in two additional cases (4-2 and 4-3) whose clinical courses are detailed in Table 7. Similar to case 4-1, PA was considered to be remitted in both patients based on the latest baseline aldosterone level of $9.6 \mathrm{ng} / \mathrm{dl}$ and renin activity of $1.4 \mathrm{ng} / \mathrm{ml}$ per $\mathrm{h}$ in case $4-2$, and $8.4 \mathrm{ng} / \mathrm{dl}$ and $2.6 \mathrm{ng} / \mathrm{ml}$ per $\mathrm{h}$, respectively, in case $4-3$. In addition, baseline ACTH and cortisol levels were $60.3 \mathrm{pg} / \mathrm{ml}$ and $9.2 \mu \mathrm{g} / \mathrm{dl}$, respectively, in case $4-2$ and $70.1 \mathrm{pg} / \mathrm{ml}$ and $10.9 \mu \mathrm{g} / \mathrm{dl}$, respectively, in case 4-3, after uneventful cessation of hormone replacement at postoperative days 146 (case 4-2) and 438 (case 4-3).

Case 5: recurrent APA within the remaining single adrenal gland $\boldsymbol{~ T h i s ~ c a s e ~ c o r r e s p o n d e d ~ t o ~ a ~ 5 6 - y e a r - o l d ~}$ man who eventually experienced recurrent APA 22 years after the first adrenalectomy for right APA at another hospital. Figure 5 shows adrenal venography performed to

Table 6 AVS findings of case 4: bilateral APA.

\begin{tabular}{|c|c|c|c|c|c|c|c|}
\hline \multirow[b]{2}{*}{ Measurements } & \multirow[b]{2}{*}{ EIV } & \multicolumn{3}{|c|}{ Right adrenal } & \multicolumn{3}{|c|}{ Left adrenal } \\
\hline & & CV & APA segment & $\begin{array}{c}\text { Non-tumor } \\
\text { segment }\end{array}$ & CV & APA segment & $\begin{array}{c}\text { Non-tumor } \\
\text { segment }\end{array}$ \\
\hline Sampling point & & 1 & 2 & 3 & 4 & 5 & 6 \\
\hline Aldosterone (ng/dl) & 48.2 & 22336 & 38031 & 722 & 9459 & 25800 & 405 \\
\hline Cortisol $(\mu \mathrm{g} / \mathrm{dl})$ & 12.7 & 1106 & 932 & 807 & 947 & 830 & 145 \\
\hline $\mathrm{A} / \mathrm{C}$ ratio & 3.80 & 20.2 & 40.79 & 0.89 & 9.99 & 31.08 & 2.80 \\
\hline SI & NA & 87.1 & 73.4 & 63.5 & 74.6 & 65.4 & 11.4 \\
\hline CSI & NA & 5.320 & 10.70 & 0.23 & 2.63 & 8.18 & 0.74 \\
\hline
\end{tabular}

A/C ratio, ratio of aldosterone over cortisol; SI, selectivity index; CSI, contralateral suppression index; EIV, external iliac vein; CV, central vein; APA, aldosterone-producing adenoma; NA, not applicable. 
Table 7 Baseline and outcome data after adrenal sparing surgery. Data were shown as mean \pm s.E.M., unless otherwise stated.

\begin{tabular}{|c|}
\hline Clinical parameters \\
\hline Days after adrenalectomy \\
\hline Baseline \\
\hline Plasma aldosterone (ng/dl) \\
\hline Plasma renin activity ( $\mathrm{ng} / \mathrm{ml}$ per $\mathrm{h})$ \\
\hline ARR (ng/dl per $\mathrm{ng} / \mathrm{ml}$ per $\mathrm{h}$ ) \\
\hline АCTH $(\mathrm{pg} / \mathrm{ml})$ \\
\hline Cortisol ( $\mu \mathrm{g} / \mathrm{dl})$ \\
\hline Baseline, urinary \\
\hline Aldosterone ( $\mu \mathrm{g} /$ day $)$ \\
\hline Free cortisol ( $\mu \mathrm{g} /$ day $)$ \\
\hline $\begin{array}{l}\text { Captopril-challenged ARR } \\
(\mathrm{ng} / \mathrm{dl} \text { per } \mathrm{ng} / \mathrm{ml} \text { per } \mathrm{h})\end{array}$ \\
\hline Cortisol with $1 \mathrm{mg} \mathrm{DST}(\mu \mathrm{g} / \mathrm{dl})$ \\
\hline $\mathrm{SBP}(\mathrm{mmHg})$ \\
\hline $\mathrm{DBP}(\mathrm{mmHg})$ \\
\hline HR (beats/min) \\
\hline $\begin{array}{l}\text { Number of anti-hypertensive } \\
\text { agents per day }\end{array}$ \\
\hline eGFR $\left(\mathrm{ml} / \mathrm{min}\right.$ per $\left.1.73 \mathrm{~m}^{2}\right)$ \\
\hline $\mathrm{Na}(\mathrm{mM})$ \\
\hline $\mathrm{K}(\mathrm{mM})$ \\
\hline $\mathrm{Cl}(\mathrm{mM})$ \\
\hline TTKG \\
\hline $\mathrm{K}$ replacement (mmol/day) \\
\hline Size of adrenal nodule \\
\hline Right adrenal nodule (mm) \\
\hline Left adrenal nodule (mm) \\
\hline
\end{tabular}

Case

Case 4-1

$\begin{array}{ccc}53.1 & 5.9 & 2.5 \\ 0.3 & 0.1 & 0.5 \\ 177.0 & 59.0 & 5.0 \\ 19.6 & 315.0 & 93.6\end{array}$

$\begin{array}{ccc}8.6 & 11.1 & 14.4\end{array}$

$\begin{array}{ccc}45.0 & 0.8 & \text { NA } \\ 225.6 & 167.0 & \text { NA }\end{array}$

$225.6 \quad 167.0 \quad N A$

96.8 NA NA

1.2 NA NA

$\begin{array}{lll}175 & 138 & 138\end{array}$

$\begin{array}{lll}96 & 74 & 86\end{array}$

$92 \quad 75 \quad 79$

4

$\begin{array}{cccc}89.3 & 63.9 & 74.1 & 58 \\ 142 & 139 & 139 & 141 \\ 4.7 & 4.6 & 4.0 & 4.5 \\ 108 & 105 & 105 & 105 \\ 10.18 & \text { NA } & \text { NA } & 3.70 \\ 139.5 & 0 & 0 & 32\end{array}$

\begin{tabular}{cc} 
Case 4-2 \\
\hline $7 \quad 728$
\end{tabular}

\begin{tabular}{cc} 
Case $4-3$ & \\
\hline $7 \quad 893$
\end{tabular}

\begin{tabular}{cc}
\hline Case 5 & \\
\hline 7 & 1065
\end{tabular}

$18.3 \quad 5.4$
0.1

$0.1 \quad 0.3$

$183.0 \quad 18.0$

$26.8 \quad 71.6$

12.2

\section{$9.0 \quad 1.4$}

$113.6 \quad 216.5$

90.0 NA NA

9.6
1.4
6.9
60.3

\section{$28.1 \quad 2.5$}

$0.3 \quad 0.1$

93.725 .0

\section{4}

2.6

2.6
3.2
70.1

24.3
14.6

20.6
0.8

70.1
10.9

$\begin{array}{lll}51.0 & 5.6 & 7.4\end{array}$

$\begin{array}{lll}0.3 & 0.8 & 5.1\end{array}$

$\begin{array}{lll}170.0 & 7.0 & 1.5\end{array}$

$\begin{array}{ccc}20.8 & 92.6 & 38.6 \\ 9.8 & 8.1 & 7.3\end{array}$

0.8 NA NA

144

89

90

$126 \quad 114$

$81 \quad 83$

$61 \quad 70$

$\begin{array}{llllll}43.4 & 0.8 & \text { NA } & 23.6 & 1.2 & \text { NA }\end{array}$

$\begin{array}{llllll}127.9 & 120.9 & \text { NA } & 106.6 & 101.4 & \text { NA }\end{array}$

96.5 NA NA 41.7 NA NA

$\begin{array}{llllll}1.5 & N A & N A & 0.8 & \text { NA } & \text { NA }\end{array}$

$\begin{array}{llllll}148 & 113 & 116 & 150 & 129 & 117\end{array}$

$\begin{array}{llllll}148 & 113 & 116 & 150 & 129 & 117 \\ 86 & 61 & 81 & 106 & 83 & 78 \\ 31 & 81 & 74 & 70 & 83\end{array}$

$\begin{array}{cccccc}8 & 61 & 81 & 74 & 70 & 83 \\ 3 & 1 & 1 & 3 & 0 & 1\end{array}$

$\begin{array}{lllllllllll}20 & \text { NA } & \text { NA } & 10 & \text { NA } & \text { NA } & 12 & \text { NA } & \text { NA } & \text { None left due to ADX } \\ 11 & \text { NA } & \text { NA } & 7 & \text { NA } & \text { NA } & 6 & \text { NA } & \text { NA } & 20 & \text { NA }\end{array}$

ARR, aldosterone-over-renin activity ratio; SBP, systolic blood pressure; DBP, diastolic blood pressure; HR, heart rate; eGFR, estimated glomerular filtration rate; TTKG, transtubular potassium gradient; ADX, adrenalectomy; NA, not applicable.

carry out S-AVS (A) and coronal CT image (B) of the left adrenal gland. A nodule was detected by CT (B, arrowheads) in the lateral segment of the left adrenal gland (A, dotted circle). Both C-AVS and S-AVS findings are summarized in Table 8. All the SI values were more than 5.0 at every sampling point in CV and tributary veins. As in case 1, S-AVS revealed excessive and suppressed secretion of aldosterone in the remaining left gland, showing A/C ratios of 23.4 at tumor segments $(>5.32$, the $\mathrm{A} / \mathrm{C}$ ratio at external iliac vein; mean $\mathrm{A} / \mathrm{C}$ ratio obtained from the two tumor segments, corresponding to sampling points 2 and 3) and 0.62 at non-tumor segment $(<5.32$, the $\mathrm{A} / \mathrm{C}$ ratio at external iliac vein) respectively. We considered that these findings could be compatible with the diagnosis of recurrent unilateral CT-detectable APA originated within the remaining left adrenal gland, rather than of unilateral hyperplasia with NFA or CT-undetectable micro-APA with non-functioning macro-adenoma.

Based on careful consideration of these clinical indicators combined with the strong desire of the patient for curative surgery, we performed partial adrenalectomy of the left adrenal gland. Following surgery, baseline
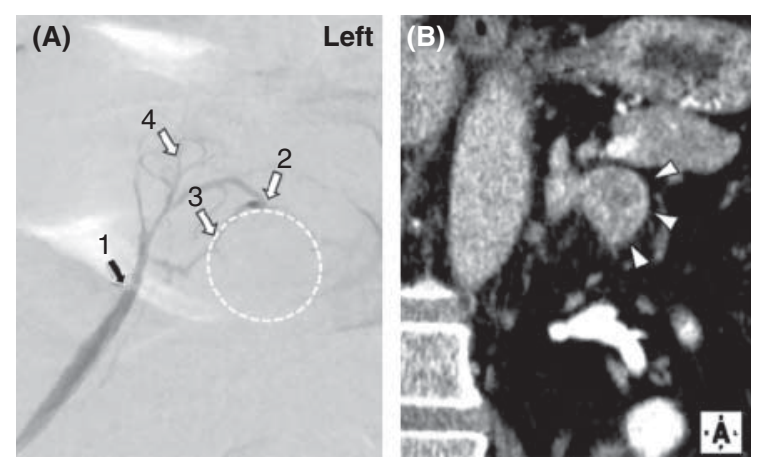

\section{Figure 5}

Adrenal venography performed to carry out S-AVS (A) and coronal CT image (B) of the left adrenal gland in a 56-year-old man who was finally diagnosed recurrent APA. The adrenal tumor was detected by $\mathrm{CT}(\mathrm{B}$, arrowheads) and projected into the venography ( $A$, dotted circle). The sampling point from a central vein is indicated by black arrow number 1 (A). Sampling points from tributary veins are indicated by white arrows 2,3 , and 4 in (A). Each number (1-4) in the venography corresponds to that of the sampling point in Table 8 . 
Table 8 AVS findings of case 5; recurrent APA within the remaining single adrenal gland.

\begin{tabular}{|c|c|c|c|c|c|}
\hline \multirow[b]{2}{*}{ Measurements } & \multirow[b]{2}{*}{ EIV } & \multicolumn{4}{|c|}{ Left adrenal } \\
\hline & & $\mathrm{CV}$ & APA segment & APA segment & Non-tumor segment \\
\hline Sampling point & & 1 & 2 & 3 & 4 \\
\hline Aldosterone (ng/dl) & 89.4 & 2803 & 17516 & 11399 & 442 \\
\hline Cortisol ( $\mu \mathrm{g} / \mathrm{dl})$ & 16.8 & 822 & 622 & 610 & 714 \\
\hline $\mathrm{A} / \mathrm{C}$ ratio & 5.32 & 3.41 & 28.17 & 18.69 & 0.62 \\
\hline SI & NA & 48.9 & 37.0 & 36.3 & 42.5 \\
\hline CSI & NA & 0.64 & 5.30 & 3.51 & 0.12 \\
\hline
\end{tabular}

$\mathrm{A} / \mathrm{C}$ ratio, ratio of aldosterone over cortisol; SI, selectivity index; CSI, contralateral suppression index; EIV, external iliac vein; CV, central vein; APA, aldosterone-producing adenoma; NA, not applicable.

plasma and urinary aldosterone levels decreased to $5.6 \mathrm{ng} / \mathrm{dl}$ and $1.2 \mu \mathrm{g} /$ day 7 days after the surgery (Table 7; case 5) suggesting the benefit of this surgical approach. His blood pressure returned to normal shortly after the surgery without medication but gradually elevated during the follow-up period and remains high to date. However, at the last follow-up on postoperative day 1065, his blood pressure was well controlled with azilsartan $20 \mathrm{mg} /$ day because he was diagnosed renoparenchymal hypertension and renal sclerosis, probably due to the long-standing PA caused by right APA and subsequent left APA. He also received glucocorticoid replacement immediately after the second surgery for 129 days without presenting signs and/or symptoms of adrenocortical insufficiency on discontinuation.

\section{Discussion}

In the present study, we retrospectively evaluated the diagnostic usefulness of S-AVS by comparing the clinical outcome between those who underwent C-AVS and those who underwent C-AVS followed by S-AVS in a cohort of 297 patients. In addition, through extensive analysis of case histories, we have identified the potential indicators and clinical presentation in which S-AVS could contribute valuable clinical information above and beyond that provided by C-AVS. This latter point is important given the time, risk and expense associated with S-AVS.

In deciding between C-AVS and S-AVS, it is important to examine the strengths, weaknesses, and risks of each approach in choosing the candidates for whom the technique is most likely to provide useful clinical information. C-AVS is already an established, specialized radiological technique and offers vital information in distinguishing unilateral from bilateral PA and, thus, deciding the ideal course of treatment (medical vs surgical). Yet, as seen in case 2 above, diagnosis based on
C-AVS may be limited, especially when dealing with aldosterone-producing lesions that are distal to the main venous networks, and S-AVS may prove superior in providing useful clinical information in such cases. In patients with unilateral disease, the current suggested management strategy based on C-AVS is laparoscopic total adrenalectomy of the affected side. This has the advantage of curing PA while retaining normal adrenal function in the contralateral adrenal. In this regard, a second advantage of S-AVS over C-AVS, especially in cases designated as being appropriate for surgical cure of PA via adrenalectomy, is the possibility to localize the tumor within the affected gland and thus perform laparoscopic partial adrenalectomy, which is performed by a novel surgical device with secure hemostat ability designed for resection of the gland. This approach further spares normal adrenal function in unilateral cases and permits surgical cure in bilateral APA cases. It should be noted that partial, as opposed to total, adrenalectomy does carry some inherent risks, and thus, candidates should be carefully screened. We have, therefore, taken this approach only in cases with CT-detectable bilateral APA and in those with recurrent APA with a past history of total adrenalectomy. Although the number of these patients proved to be quite small within the larger population of PA cases, the overall benefits in terms of outcomes and quality of life confirm the importance of this technique in this subset.

There are some limitations to our study. First, the selected cohort may have led us to underestimate the true utility of S-AVS in a wider pool of PA patients. Second, the measurement and interpretation of steroid levels in both sampling approaches may have been biased. Immunoassays have inherent limitations; thus, in light of the endogenous differences in the laterality of cortisol secretion, the use of cortisol in the denominator of the SI and LI could have prevented accurate subtyping of PA, 
as previously reported $(20,21)$. Because the common denominator of both SI and LI determined by C-AVS is cortisol level, the endogenous difference in laterality of cortisol secretion could lead to misinterpretation of S-AVS findings and affect subsequent sub-typing of PA determined by SI and LI, as reported in previous studies $(20,21)$. Therefore, only the absolute concentrations of aldosterone and cortisol obtained by S-AVS could enable us to evaluate the precise intra-adrenal steroidogenic distribution, i.e., which tumor or intra-adrenal segment is responsible for hyperaldosteronism or autonomous cortisol production.

The future development and improvement of S-AVS may involve some of the following changes. As mentioned above, immunoassays could result in clinically substantial errors in measurement, especially at high concentrations as detected in adrenal effluents, and the clinical usefulness of a novel assay using mass spectrometry has been proposed for such cases $(22,23)$. In previous studies including ours $(24,25,26,27)$, some PA patients were found to present autonomous adrenal cortisol overproduction. It has been also proposed that in PA associated with autonomous adrenal cortisol overproduction, plasma metanephrine measured in samples from the adrenal veins would provide a good alternative to cortisol measurement for calculating SI and LI (28).

According to the clinical guideline established by the Endocrine Society (29), a relatively large proportion of hypertensive patients should undergo AVS. However, even standard AVS (or C-AVS) is already, clinically and practically, considered difficult for most angiographers and this indeed limits the widespread use of AVS for the diagnosis of PA subtypes. S-AVS is even more difficult and cumbersome, and therefore, application of S-AVS is expected to be limited to very few centers with highly experienced and dedicated radiologists. A further limitation to the widespread adoption of S-AVS is that both estimated costs and rate of extravasation during the segmental sampling were clearly higher in our cohort. These factors underline the fact that larger studies are needed to consider patient selection and clinical criteria that justify the adoption of S-AVS in regards to risk, clinical benefit, and cost effectiveness.

In summary, S-AVS might serve to determine intraadrenal variations in terms of aldosterone secretion and extend the surgical indication for treatment to patients with bilateral APA, as reported in the present study. We conclude, therefore, that the candidates for S-AVS should be considered carefully but its application should be extended to referral centers of PA patients in the near future because of its high diagnostic utility in bilateral APA and other disorders.

\section{Declaration of interest}

The authors declare that there is no conflict of interest that could be perceived as prejudicing the impartiality of the research reported.

\section{Funding}

This research did not receive any specific grant from any funding agency in the public, commercial or not-for-profit sector.

\section{Acknowledgements}

We thank Yasuko Tsukada, Akane Sugawara, Mika Ainoya, Kumi Kikuchi, and Hiroko Kato for their secretarial assistance.

\section{References}

1 Savard S, Amar L, Plouin PF \& Steichen O. Cardiovascular complications associated with primary aldosteronism: a controlled cross-sectional study. Hypertension 201362 331-336. (doi:10.1161/HYPERTENSIONAHA.113.01060)

2 Mulatero P, Monticone S, Bertello C, Viola A, Tizzani D, Iannaccone A, Crudo V, Burrello J, Milan A, Rabbia F et al. Long-term cardio- and cerebrovascular events in patients with primary aldosteronism. Journal of Clinical Endocrinology and Metabolism 201398 4826-4833. (doi:10.1210/jc.2013-2805)

3 Young WF, Stanson AW, Thompson GB, Grant CS, Farley DR \& van Heerden JA. Role for adrenal venous sampling in primary aldosteronism. Surgery 2004136 1227-1235. (doi:10.1016/j.surg.2004. 06.051)

4 Satoh F, Abe T, Tanemoto M, Nakamura M, Abe M, Uruno A, Morimoto R, Sato A, Takase K, Ishidoya S et al. Localization of aldosterone-producing adrenocortical adenomas: significance of adrenal venous sampling. Hypertension Research 200730 1083-1095. (doi:10.1291/hypres.30.1083)

5 Rossi GP, Barisa M, Allolio B, Auchus RJ, Amar L, Cohen D, Degenhart C, Deinum J, Fischer E, Gordon R et al. The Adrenal Vein Sampling International Study (AVIS) for identifying the major subtypes of primary aldosteronism. Journal of Clinical Endocrinology and Metabolism 201297 1606-1614. (doi:10.1210/jc.2011-2830)

6 Rossi GP, Auchus RJ, Brown M, Lenders JW, Naruse M, Plouin PF, Satoh F \& Young WF Jr. An expert consensus statement on use of adrenal vein sampling for the subtyping of primary aldosteronism. Hypertension 201463 151-160. (doi:10.1161/HYPERTENSIONAHA. 113.02097)

7 Monticone S, Viola A, Rossato D, Veglio F, Reincke M, GomezSanchez C \& Mulatero P. Adrenal vein sampling in primary aldosteronism: towards a standardised protocol. Lancet. Diabetes \& Endocrinology 20153 296-303. (doi:10.1016/S2213-8587(14)70069-5)

8 Stowasser M, Taylor PJ, Pimenta E, Ahmed AH \& Gordon RD. Laboratory investigation of primary aldosteronism. Clinical Biochemist. Reviews 201031 39-56.

9 Monticone S, Satoh F, Viola A, Fischer E, Vonend O, Bernini G, Lucatello B, Quinkler M, Ronconi V, Morimoto R et al. Aldosterone suppression on contralateral adrenal during adrenal vein sampling does not predict blood pressure response after adrenalectomy. Journal of Clinical Endocrinology and Metabolism 201499 4158-4166. (doi:10.1210/ jc.2014-2345) 
10 Wolley MJ, Gordon RD, Ahmed AH \& Stowasser M. Does contralateral suppression at adrenal venous sampling predict outcome following unilateral adrenalectomy for primary aldosteronism? A retrospective study Journal of Clinical Endocrinology and Metabolism 2015100 1477-1484. (doi:10.1210/jc.2014-3676)

11 Mulatero P, Bertello C, Sukor N, Gordon RD, Rossato D, Daunt N, Leggett D, Mengozzi G, Veglio F \& Stowasser M. Impact of different diagnostic criteria during adrenal vein sampling on reproducibility of subtype diagnosis in patients with primary aldosteronism. Hypertension 201055 667-673. (doi:10.1161/HYPERTENSIONAHA.109. 146613)

12 Ono Y, Nakamura Y, Maekawa T, Felizola SJ, Morimoto R, Iwakura Y, Kudo M, Seiji K, Takase K, Arai Y et al. Different expression of $11 \beta$ hydroxylase and aldosterone synthase between aldosterone-producing microadenomas and macroadenomas. Hypertension 201464 438-444. (doi:10.1161/HYPERTENSIONAHA.113.02944)

13 Wu VC, Chueh SC, Chang HW, Lin WC, Liu KL, Li HY, Lin YH, Wu KD $\&$ Hsieh BS. Bilateral aldosterone-producing adenomas: differentiation from bilateral adrenal hyperplasia. Quarterly Journal of Medicine 2008 101 13-22. (doi:10.1093/qjmed/hcm101)

14 Watanabe N, Tsunoda K, Sasano H, Omata K, Imai Y, Ito S \& Abe K. Bilateral aldosterone-producing adenomas in two patients diagnosed by immunohistochemical analysis of steroidogenic enzymes. Tohoku Journal of Experimental Medicine 1996179 123-129. (doi:10.1620/tjem. 179.123)

15 Chung S-D, Huang K-H, Yu H-J, Wu KD \& Chueh SC. Diagnosis of bilateral aldosterone-producing adenomas. Kidney International 2007 72 228. (doi:10.1038/sj.ki.5002214)

16 Nishikawa T, Matsuzawa Y, Saito J \& Omura M. Is it possible to extirpate cardiovascular events in primary aldosteronism after surgical treatment? Japanese Clinical Medicine 20101 21-23. (doi:10.4137/JCM. S6316)

17 Omura M, Saito J, Matsuzawa Y \& Nishikawa T. Supper-selective ACTH-stimulated adrenal vein sampling is necessary for detecting precisely functional state of various lesions in unilateral and bilateral adrenal disorders, inducing primary aldosteronism with subclinical Cushing's syndrome. Endocrine Journal 201158 919-920. (doi:10.1507/ endocrj.EJ11-0210)

18 Satoh F, Morimoto R, Ono Y, Iwakura Y, Omata K, Kudo M, Takase K, Seiji K, Sasamoto H, Honma S et al. Measurement of peripheral plasma 18-oxocortisol can discriminate unilateral adenoma from bilateral diseases in patients with primary aldosteronism. Hypertension 201565 1096-1102. (doi:10.1161/HYPERTENSIONAHA.114.04453)

19 Satani N, Ota H, Seiji K, Morimoto R, Kudo M, Iwakura Y, Ono Y, Nezu M, Omata K, Ito $\mathrm{S}$ et al. Intra-adrenal aldosterone secretion: segmental adrenal venous sampling for localization. Radiology 2015. In Press. (doi:10.1148/radiol.2015142159)

20 Hiraishi K, Yoshimoto T, Tsuchiya K, Minami I, Doi M, Izumiyama H, Sasano H \& Hirata Y. Clinicopathological features of primary aldosteronism associated with subclinical Cushing's syndrome. Endocrine Journal 201158 543-551. (doi:10.1507/endocrj.K10E-402)

21 Nishikawa T, Omura M, Satoh F, Shibata H, Takahashi K, Tamura N, Tanabe A, Task Force Committee on Primary Aldosteronism \& The Japan Endocrine Society . Guidelines for the diagnosis and treatment of primary aldosteronism - the Japan Endocrine Society 2009. Endocrine Journal 201158 711-721. (doi:10.1507/endocrj.EJ11-0133)

22 Yamashita K, Okuyama M, Nakagawa R, Honma S, Satoh F, Morimoto R, Ito S, Takahashi M \& Numazawa M. Development of sensitive derivatization method for aldosterone in liquid chromatography-electrospray ionization tandem mass spectrometry of corticosteroids. Journal of Chromatography. A 20081200 114-121. (doi:10.1016/j.chroma.2008.05.034)

23 Turpeinen U, Hämäläinen E \& Stenman UH. Determination of aldosterone in serum by liquid chromatography-tandem mass spectrometry. Journal of Chromatography. B, Analytical Technologies in the Biomedical and Life Sciences 2008862 113-118. (doi:10.1016/j.jchromb. 2007.11.005)

24 Fallo F, Bertello C, Tizzani D, Fassina A, Boulkroun S, Sonino N, Monticone S, Viola A, Veglio F \& Mulatero P. Concurrent primary aldosteronism and subclinical cortisol hypersecretion: a prospective study. Journal of Hypertension 201129 1773-1777. (doi:10.1097/HJH Ob013e32834937f3)

25 Morimoto R, Kudo M, Murakami O, Takase K, Ishidoya S, Nakamura Y, Ishibashi T, Takahashi S, Arai Y, Suzuki T et al. Difficult-to-control hypertension due to bilateral aldosterone-producing adrenocortical microadenomas associated with a cortisol-producing adrenal macroadenoma. Journal of Human Hypertension 201125 114-121. (doi:10.1038/jhh.2010.35)

26 Satoh F, Murakami O, Takahashi K, Ueno J, Nishikawa T, Abe K, Mouri T \& Sasano H. Double adenomas with different pathological and hormonal features in the left adrenal gland of a patient with Cushing's syndrome. Clinical Endocrinology 199746 227-234. (doi:10.1046/j. 1365-2265.1997.1130930.x)

27 Kawasaki Y, Ishidoya S, Kaiho Y, Ito A, Satoh F, Morimoto R, Nakagawa H \& Arai Y. Laparoscopic simultaneous bilateral adrenalectomy: assessment of feasibility and potential indications. International Journal of Urology 201118 762-767. (doi:10.1111/j. 1442-2042.2011.02846.x)

28 Dekkers T, Deinum J, Schultzekool LJ, Blondin D, Vonend O, Hermus AR, Peitzsch M, Rump LC, Antoch G, Sweep FC et al. Plasma metanephrine for assessing the selectivity of adrenal venous sampling. Hypertension 201362 1152-1157. (doi:10.1161/HYPERTENSIONAHA. 113.01601)

29 Funder JW, Carey RM, Fardella C, Gomez-Sanchez CE, Mantero F, Stowasser M, Young WF Jr, Montori VM \& Endocrine Society. Case detection, diagnosis, and treatment of patients with primary aldosteronism: an Endocrine Society clinical practice guideline. Journal of Clinical Endocrinology and Metabolism 200893 3266-3281. (doi:10.1210/ jc.2008-0104)

Received 30 December 2014

Revised version received 29 June 2015

Accepted 20 July 2015 